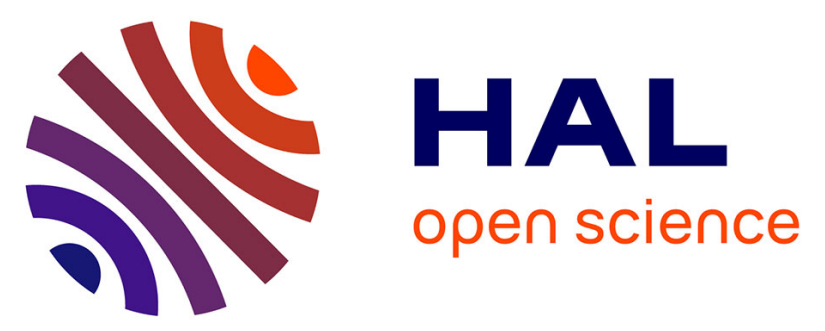

\title{
Combined Operation of an Unified Power Quality Conditioner and a Superconducting Magnetic Energy Storage System for Power Quality Improvement
} Nuno Amaro, Luís Casimiro, João Murta Pina, João Martins, José M. Ceballos

\section{To cite this version:}

Nuno Amaro, Luís Casimiro, João Murta Pina, João Martins, José M. Ceballos. Combined Operation of an Unified Power Quality Conditioner and a Superconducting Magnetic Energy Storage System for Power Quality Improvement. 6th Doctoral Conference on Computing, Electrical and Industrial Systems (DoCEIS), Apr 2015, Costa de Caparica, Portugal. pp.374-382, 10.1007/978-3-319-167664_40. hal-01343506

\author{
HAL Id: hal-01343506 \\ https://hal.inria.fr/hal-01343506
}

Submitted on 8 Jul 2016

HAL is a multi-disciplinary open access archive for the deposit and dissemination of scientific research documents, whether they are published or not. The documents may come from teaching and research institutions in France or abroad, or from public or private research centers.
L'archive ouverte pluridisciplinaire HAL, est destinée au dépôt et à la diffusion de documents scientifiques de niveau recherche, publiés ou non, émanant des établissements d'enseignement et de recherche français ou étrangers, des laboratoires publics ou privés. 


\title{
Combined Operation of an Unified Power Quality Conditioner and a Superconducting Magnetic Energy Storage System for Power Quality Improvement
}

\author{
Nuno Amaro ${ }^{1}$, Luís Casimiro, João Murta Pina ${ }^{1}$, João Martins ${ }^{1}$, José Maria Ceballos ${ }^{2}$ \\ ${ }^{1}$ Centre of Technology and Systems, Faculdade de Ciências e Tecnologia, Universidade \\ Nova de Lisboa, 2829-516 Caparica, Portugal \\ 2 "Benito Mahedero" Group of electrical Applications of Superconductors, Escuela de \\ Ingenierías Industriales, Universidad de Extremadura, Avenida de Elvas s/n, 06006, Badajoz, \\ Spain
}

nma19730@campus.fct.unl.pt, \{jmmp, jf.martins $\} @$ fct.unl.pt, jmceba@unex.es

\begin{abstract}
Superconducting Magnetic Energy Storage (SMES) is a class of promising superconducting devices, considering its possible applications in power systems. This paper describes a combination of a SMES with a Unified Power Quality Conditioner (UPQC) for power quality improvement in an electric grid. The SMES device is used to improve the UPQC performance by increasing the stored energy in the DC link. Several power quality faults including voltage sags and current harmonics are simulated and the system behavior is demonstrated. This hybrid system has the advantage of being able to overcome different kinds of power quality faults with higher performance than as a set of individual systems, thus increasing power quality in electric grids.
\end{abstract}

Keywords: SMES, UPQC, Power Quality

\section{Introduction}

In modern electric grids, power quality is a very important topic, considering the high dissemination of microprocessors and electronic devices, which require a highly stable power connection. In this context, power quality faults like voltage sags/swells, frequency oscillations and harmonic distortion, amongst others, must be minimized or, if possible, eliminated [1]. Amongst the several classes of devices that overcome power quality issues, active power filters already play an important role and are expected to be the main contributor to deal with such problems in the future, due to their flexibility [2]. The Unified Power Quality Conditioner (UPQC) is one of the most flexible devices because it consists of a combination of a series and a shunt active power filters, allowing a simultaneous compensation of voltage and current [3]. The two filters (series and shunt) are connected by means of a DC link with a capacitor. The capacitor is a very important element because it stores energy allowing 
the DC voltage to maintain a required level, which is determinant in the overall system performance [4].

Superconducting Magnetic Energy Storage (SMES) systems are one class of devices based on the phenomena of superconductivity that are expected to have more applications in power systems [5][6]. By means of a superconducting coil it is possible to store energy and use it whenever it is necessary. Although these devices have a lower energy density when compared to other energy storage systems (like batteries), their power density is very high and the device can be fully discharged in a few milliseconds. This characteristic makes the SMES a power device instead of an energy device [7]. SMES can thus be used to address power quality issues and several projects are already running in this area, including voltage sags/swells compensation [8], mitigation of frequency oscillations [9] and UPS applications [10, 11].

The integration of SMES and FACTS (Flexible AC Transmission System) devices has already been discussed and there are several possible advantages in doing it [12]. The main advantage resides in the fact that with an SMES it is possible to add real energy storage capabilities to the whole system (SMES + FACTS device), which will increase its performance and applicability [13]. Since FACTS devices already contain a DC link, the overall cost of the SMES unit becomes lower because its Power Converter System (PCS) becomes simpler. In fact, the PCS becomes only a chopper converter connected to the DC link, eliminating the necessity to have a bidirectional power converter (rectifier and inverter) in the SMES. Some studies also indicate that through the addition of a SMES unit, it is possible to decrease the power rating of the FACTS device, also decreasing its costs [14].

Considering the various advantages in adding a SMES unit to a FACTS device, a system consisting of an UPQC with a SMES unit connected to its DC link is presented in this work. The system was designed to overcome two different power quality issues: voltage sags and harmonic distortion. Matlab/Simulink simulations are presented to mitigate the aforementioned power quality issues.

\section{Relation to Cloud-based Engineering Systems}

The evolution in power systems through the last years is leading to the creation of a new intelligent power grid usually known as Smart Grid [15]. In this new concept of power grid, both energy and information are expected to flow up- and downstream. With the increasing penetration of microprocessors and electronics the requirements for energy quality are also increasing and it is necessary to have full monitoring and control of the grid [16]. In such context, devices that increase power quality acquire great importance in power systems. This paper aims to contribute to the application of such devices, by presenting a hybrid device, which not only has power quality enhancement capabilities but also provides the possibility to storage energy. Such devices must be fully controllable and their successful dissemination also depends on the success of cloud-based software for security and operation control [17]. In this sense, and considering that all devices present in future power systems are expected to communicate with each other, cloud-based engineering systems are of great importance if smart grids are to be successfully implemented $[18,19]$. 


\section{System Description}

The studied system is schematized in Fig. 1. The series active filter is connected close to the power source and the shunt filter close to the load. Although a different configuration could be chosen, this one allows a better controllability of the DC link voltage [20], which in this case is beneficial because there is the SMES unit connected to this link. The shunt filter converter must be bidirectional in order to allow a full controllability of the DC voltage.

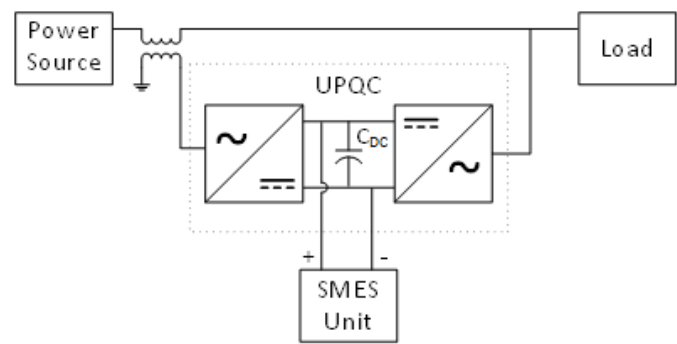

Fig. 1 Implemented system

\subsection{UPQC}

The UPQC is a very complete device, regarding its ability to deal with power quality issues. The combination of a series and a shunt active filters allows control of current and voltage. Both filters are connected through a DC link that contains a capacitor. The DC voltage in this link must be maintained at a certain level in order to allow full controllability of the system, and to charge the superconducting coil of the SMES unit. The implemented UPQC and its controller are shown in Fig. 2.

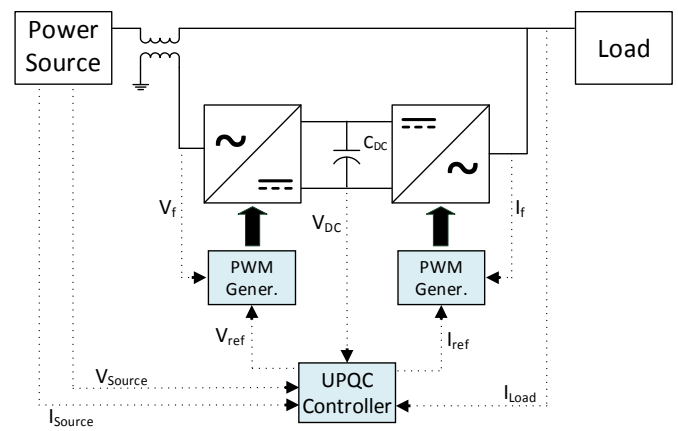

Fig. 2 Implemented UPQC

The pulse width modulation (PWM) signals for the two converters in the series and shunt active power filters are generated according to voltage and current reference signals, respectively. The reference signal for the current in the shunt active power filter is generated following a Synchronous Reference Frame method [4]. The reference signal (used to generate the PWM signal) of the voltage in the series power filter is generated by a "feedforward" control method, comparing the voltage of the 
filter to a defined reference value. The DC link capacitor, $C_{D C}$, has a value of $20 \mu \mathrm{F}$, calculated following the formulation presented in [21].

\subsection{SMES}

A SMES system is composed of three main sub-systems: a superconducting coil, which stores energy in its magnetic field, a Power Converter System (PCS) responsible for the exchange of energy between the coil and the grid where it connects and a Control System (CS) that manages energy exchanges. Fig. 3 depicts the usual system configuration.

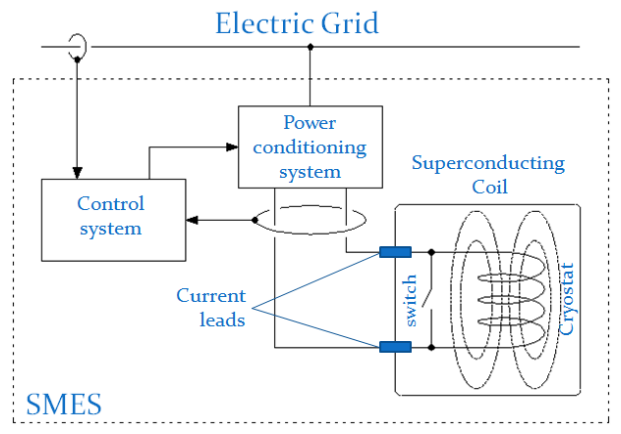

Fig. 3 SMES system constitution.

The PCS system usually consist of a bidirectional power electronics interface (with rectifying and inverting capabilities). However, in this specific case, because the SMES is connected to a DC link, only a DC/DC converter is necessary (a chopper converter). The used SMES configuration is depicted in Fig. 4. The superconducting coil was simulated as simple inductance. In a real system, the total resistance of the system might be non-negligible (due to e.g. current leads or resistive contacts), but as a first approach it is not necessary to consider this resistance.

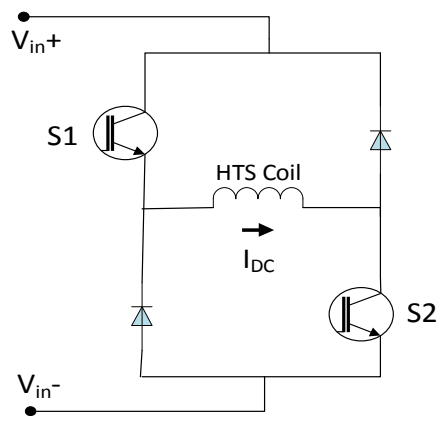

Fig. 4. SMES unit

Since the PCS of the implemented SMES is rather simple when compared to a PCS when the SMES is connected to an AC grid, the control system also becomes simpler 
because it is only necessary to control the two power electronic switches (in this case IGBTs) that form the chopper converter. The control must allow three different operation modes: charge, discharge and persistent. Charge and discharge mode correspond to charging and discharging the superconducting coil, respectively, and the persistent mode corresponds to a situation where the coil is already fully charged and current flow is maintained in a continuous mode. The control of the switches S1 and $\mathrm{S} 2$ defines the operating mode:

- S1 and S2 closed: charging mode;

- $\mathrm{S} 1$ open and S2 closed: persistent mode;

- S1 and S2 open: discharging mode.

In a system where the SMES is operating alone, the control of the chopper is very straightforward. The system enters a charging mode till the current in the coil reaches the desired value and then the persistent mode is activated. The discharge mode is used when there is a fault in the grid. However, in the case of a joint operation with an UPQC, the control must take care of other situations as well. The UPQC has a DC link in which the DC value cannot decrease under a certain value, otherwise the shunt filter enters a non-controllable situation [21]. This means that the charging process of the SMES must take into account the DC voltage value. The persistent and discharging modes operate in the same way as in a regular SMES system.

The main characteristics from the SMES unit simulated in this work are presented in table 1. Such characteristics were obtained following the method presented in [22].

Table 1. Characteristics of the simulated SMES unit.

\begin{tabular}{lc}
\hline Characteristic & Value \\
\hline Number of pancake coils & 4 \\
Total inductance $(\mathrm{H})$ & 0.28 \\
Rated current value $(\mathrm{A})$ & 70 \\
Total length of SC tape $(\mathrm{m})$ & 800 \\
\hline
\end{tabular}

The maximum stored energy using this coil is $686 \mathrm{~J}$. Using only the capacitor in the DC link of the UPQC, the maximum stored energy was $4.9 \mathrm{~J}$, which strongly limits applications of this system. The addition of a SMES unit allowed greatly increasing stored energy, which means that the system can overcome different kinds (with longer duration) of power quality faults.

\section{Simulation Results}

To evaluate the UPQC+SMES system performance, Matlab/Simulink simulations were performed, considering two different kinds of power quality problems: voltage sags and harmonic distortion (addition of $5^{\text {th }}$ order harmonics). The simulated system is the one already depicted in Fig. 1. 


\subsection{Voltage Sags/Swells Compensation}

Voltage sags of different levels were simulated using a three phase programmable voltage source in Simulink. Fig. 5 shows source and load voltages for a voltage sag of $50 \%$, during two and a half cycles $(50 \mathrm{~ms})$. It is possible to see that the system successfully compensate the voltage sag, allowing maintaining voltage at the load during the whole period of the fault.

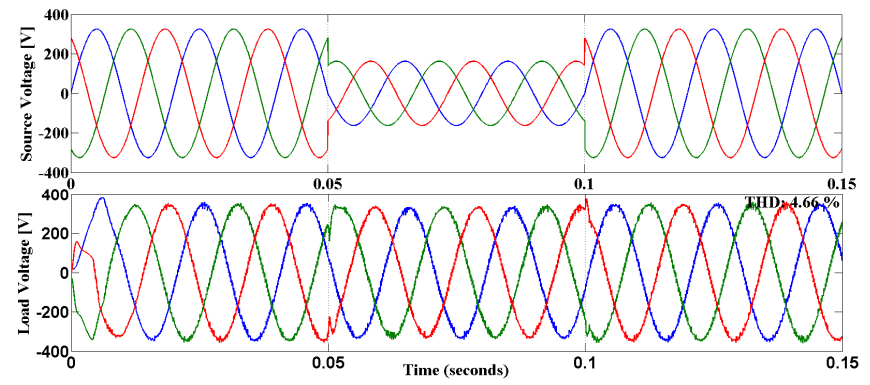

Fig. 5. Voltage sag compensation

The voltage in the DC link of the UPQC, which is used to charge the SMES coil, is shown in Fig. 6. The SMES is charged guaranteeing that voltage does not drops below a specific value, namely $700 \mathrm{~V}$. This was chosen in order to have always a DC voltage above the minimum value that allows full controllability of the power filters, which in this case was calculated as $648 \mathrm{~V}$, following the formulation presented in [21]. The consecutive voltage drops shown in the figure correspond to the charging process of the SMES. During the charging process, current flows to the superconducting coil, decreasing the amount of power at the DC link, thus forcing the DC link voltage to go down. Fig. 6 also shows the evolution of the current in the SMES system, which decreases around $13 \mathrm{~A}$ in order to compensate the voltage sag (the SMES is in discharge mode during this time).

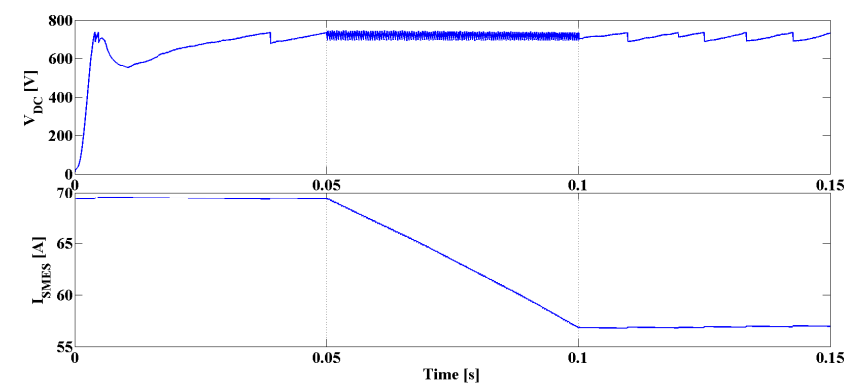

Fig. 6. Voltage in the DC link and current at the SMES coil during a voltage sag 


\subsection{Harmonic Distortion Mitigation}

Another important fault that can occur in a power grid is harmonic distortion. The programmable three phase voltage source from Simulink was again used to add a $5^{\text {th }}$ order harmonic with 0.25 pu content to the voltage signal. This corresponds to a THD of $14.92 \%$. Voltages at source and load for this scenario can be seen in Fig. 7. The system can compensate the harmonic distortion and the load is barely affected by it. The THD at the load is $4.82 \%$ during the fault.

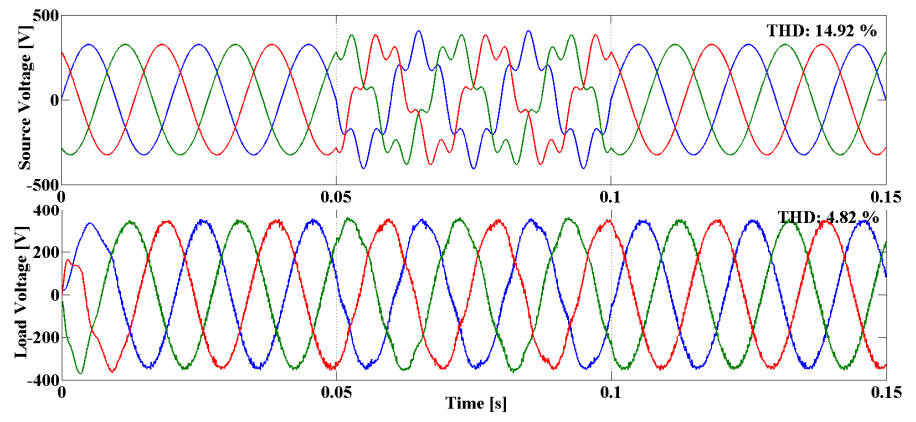

Fig. 7. Compensation of harmonic distortion in the system

\section{Conclusion}

A combination of an UPQC and a SMES device was presented in this paper and simulation results indicate that the hybrid system can be used to overcome power quality issues in an electric grid. The addition of an SMES unit to the UPQC has several advantages: by adding energy store capabilities, the SMES increases the application range of the UPQC (in this example, the stored energy increased from 4.9 to $686 \mathrm{~J})$. The overall cost of the UPQC device becomes lower because with the combination of a SMES its power rating decreases. Since the SMES is connected to a DC link, the PCS becomes less costly and the control system also becomes simpler. The control scheme of the full system is very similar to those of the two systems operating alone, with only the additional requirement on the DC voltage when charging the SMES coil.

Two different power quality faults (voltage sags and harmonic distortion of the $5^{\text {th }}$ order) were simulated and results indicate that the system can overcome those faults, without any noticeable change of voltage and current at the load. Such system can improve power quality in electric grids and thus has a very large spectrum of applications. 


\section{References}

1. EURELECTRIC: Power Quality in European Electricity Supply Networks., (2003).

2. Akagi, H.: New trends in active filters for power conditioning. IEEE Trans. Ind. Appl. 32, 1312-1322 (1996).

3. Akagi, H., Watanabe, E.H., Aredes, M.: Instantaneous Power Theory and Applications to Power Conditioning. John Wiley \& Sons, Inc., Hoboken, NJ, USA (2007).

4. Rashid, M.H. ed: Power Electronics Handbook. Elsevier (2011).

5. Amaro, N., Murta Pina, J., Martins, J., Ceballos, J.M.: SUPERCONDUCTING MAGNETIC ENERGY STORAGE - A Technological Contribute to Smart Grid Concept Implementation. Proceedings of the 1st International Conference on Smart Grids and Green IT Systems. pp. 113-120. SciTePress - Science and and Technology Publications (2012).

6. Xiao, L., Dai, S., Lin, L., Zhang, J., Guo, W., Zhang, D., Gao, Z., Song, N., Teng, Y., Zhu, Z., Zhang, Z., Zhang, G., Zhang, F., Xu, X., Zhou, W.: Development of the World's First HTS Power Substation. IEEE Trans. Appl. Supercond. 22, 5000104-5000104 (2012).

7. Tixador, P., Deleglise, M., Badel, a., Berger, K., Bellin, B., Vallier, J.C., Allais, a., Bruzek, C.E.: First Tests of a 800 kJ HTS SMES. IEEE Trans. Appl. Supercond. 18, 774-778 (2008).

8. Kim, H.J., Seong, K.C., Cho, J.W., Bae, J.H., Sim, K.D., Kim, S., Lee, E.Y., Ryu, K., Kim, S.H.: $3 \mathrm{MJ} / 750 \mathrm{kVA}$ SMES System for Improving Power Quality. IEEE Trans. Appl. Supercond. 16, 574-577 (2006).

9. Xian, W., Yuan, W., Yan, Y., Coombs, T. a.: Minimize frequency fluctuations of isolated power system with wind farm by using superconducting magnetic energy storage. PEDS Conference. pp. 1329-1332. IEEE (2009).

10. Aware, M., Sutanto, D.: SMES for Protection of Distributed Critical Loads. IEEE Trans. Power Deliv. 19, 1267-1275 (2004).

11. Tixador, P., Bellin, B., Deleglise, M., Vallier, J.C., Bruzek, C.E., Allais, A.., Saugrain, J.M.: Design and First Tests of a 800 kJ HTS SMES. IEEE Trans. Appl. Supercond. 17, 1967-1972 (2007).

12. Torre, W., Eckroad, S.: Improving power delivery through the application of superconducting magnetic energy storage (SMES). 2001 IEEE Power Engineering Society Winter Meeting. Conference Proceedings (Cat. No.01CH37194). pp. 81-87. IEEE (2001).

13. Chen, L., Liu, Y., Arsoy, A.B., Ribeiro, P.F., Steurer, M., Iravani, M.R.: Detailed Modeling of Superconducting Magnetic Energy Storage (SMES) System. IEEE Trans. Power Deliv. 21, 699-710 (2006).

14. EPRI: West Coast Utility Transmission Benefits Of Superconducting Magnetic Energy Storage. (1996).

15. IEA, (International Energy Agency): Smart Grids - Technology Roadmap. (2011).

16. Ipakchi, A., Albuyeh, F.: Grid of the future. IEEE Power Energy Mag. 7, 52-62 (2009).

17. Zhang, P., Li, F., Bhatt, N.: Next-Generation Monitoring, Analysis, and Control for the Future Smart Control Center. IEEE Trans. Smart Grid. 1, 186-192 (2010).

18. Markovic, D.S., Zivkovic, D., Branovic, I., Popovic, R., Cvetkovic, D.: Smart power grid and cloud computing. Renew. Sustain. Energy Rev. 24, 566-577 (2013).

19. Yigit, M., Gungor, V.C., Baktir, S.: Cloud Computing for Smart Grid applications. Comput. Networks. 70, 312-329 (2014).

20. Nielsen, J.G., Blaabjerg, F.: A Detailed Comparison of System Topologies for Dynamic Voltage Restorers. IEEE Trans. Ind. Appl. 41, 1272-1280 (2005).

21. Teke, A.: Unified Power Quality Conditioner: Design, Simulation and Experimental Analysis., (2011).

22. Amaro, N., Pina, J.M., Martins, J., Ceballos, J.M., Alvarez, A.: A Fast Algorithm for Initial Design of HTS Coils for SMES Applications. IEEE Trans. Appl. Supercond. 23, 49001044900104 (2013). 